\title{
Profiling Phase of Bako Peninsula Residents
}

\author{
Aisyah Abu Bakar, Mariana Mohamed Osman, \\ Syahriah Bachok, Ismawi Zen \\ International Islamic University Malaysia, Malaysia
}

Isya.ab@gmail.com

\begin{abstract}
In the era of urban regeneration, among many challenges faced by the policy makers is to engage the local community in planning processes. Among many action plans involving the local community is Social Impact Assessment (SIA). The research aimed to underline issues discovered during the profiling phase of the SIA process conducted in Bako Peninsula. The methodology of the research is case study and survey questionnaire. The research discovered issues attributed to social trends and cultural diversity of residents. The findings influenced the next step of the SIA process and future development of Bako Peninsula.
\end{abstract}

Keywords: Social Impact Assessment, Profiling Phase, Bako Peninsula

eISSN 2514-7528 @ 2018. The Authors. Published for AMER ABRA cE-Bs by e-International Publishing House, Ltd., UK. This is an open-access article under the CC BY-NC-ND license (http://creativecommons.org/licenses/bync-nd/4.0/). Peer-review under responsibility of AMER (Association of Malaysian Environment-Behaviour Researchers), ABRA (Association of Behavioural Researchers on Asians) and CE-Bs (Centre for EnvironmentBehaviour Studies), Faculty of Architecture, Planning \& Surveying, Universiti Teknologi MARA, Malaysia.

DOI: https://doi.org/10.21834/jabs.v3i10.309 


\subsection{Introduction}

The fundamental recognition of Social Impact Assessment (SIA) is that it is a subfield of Environmental Impact Assessment (EIA). EIA refers to the assessment of an impending impact of planning intervention that contributed significant change to the concerned environment. While SIA is the course of forecasting and mitigating the anticipated and unanticipated consequences of development on social aspects of the environment. In other words, EIA is the hedge against the uncertainty of the planning process while SIA broadened the hedge into the social science aspects. SIA initiated in America in the early 1970s while the official inception of SIA in Malaysia was in 2003. At that point, Malaysia National Social Policy recognized SIA and entailed utilization of the document in the planning of all public and private development activities (Ahmad, 2009).

A Structural Master Plan Study 2013 to 2030 conducted at Bako Peninsula. The Master Plan Study intended to recognize and analyze existing issues in Bako Peninsula as well as suggesting proposals towards solving the recognized issues, reaching potentials of Bako Peninsula as well as the elevating quality of lives of the residents. The fieldwork of the study undertook survey questionnaires and statistical analyses. The aim of the research was to identify and assess issues facing the residents of Bako Peninsula at the profiling phase of the SIA process. The objectives are (i) to determine the demographic and socioeconomic trends of Bako Penisula residents, (ii) to determine association between Settlement Types and Accessibility to Social Amenities, (iii) to determine association between Settlement Types and Infrastructure Issues, (iv) to determine association between Economic Activities and Benefits of Natural Resources, and (v) to determine the employment scenarios of Bako Peninsula residents.

\subsection{Literature Review}

SIA combines social research, public involvement as well as planning and management of social change. The analysis of the SIA documents includes the likelihoods, durations and distributions of social impacts across geographical areas and within communities. Accordingly, (i) communication, (ii) transparency, (iii) collaboration, (iv) inclusiveness and (iv) integrity are among the top principles in the majority of SIA guidelines (Ahmad, 2009). It is important to recognize the distinction between social impacts and SIA. While the former refers to consequences of development on social aspects, the latter is the process of forecasting, analyzing, managing and mitigating the effects of development on social aspects (Ahmad, 2009). Thus, legitimacy and transparency of public participation in the SIA processes are crucial (Sharifah Norazizan Syed Abd. Rashid, 2002).

Urban regeneration refers to the course of reinvigorating an urban area. The process involved considerable financial investment in developing infrastructure, social amenities and facilities of the urban areas. However, due to conventional technology that pays close attention to construction and structures, adapting urban spaces to the natural setting was highly challenging (Hanaki, 2008). In this sense, natural setting refers to a wide range of social, economic and environmental aspects. One of the highly mentioned consequences of 
urban regeneration were the loss of identity and diversity regarding communities, human activities and land uses (Clantonio and Dixon, 2009; Granger, 2010). For that reason, SIA played a crucial part in mitigating issues that are impacting the social setting before the intended development.

The very first principle of SIA was to comprehend the impacted persons of the proposed projects (Vanclay, 2003). The process consists of primary phases of profiling, formulation of alternatives, forecasting and estimation of the degree of impacts, mitigation, management and evaluation (Ahmad, 2009).

In a simple understanding, diversity is differences. A broader definition of diversity covers human differences in personality, commitment and decision-making styles (Loden and Rosener, 1991). Commonly examined demographic and socio-economic factors identified human differences (O'Neil, 2006; Pietrobruno, 2009), which are important variables in the data gathering and analyzing processes of SIA.

The significance of demographic and socioeconomic data from a particular community lies in the discovered key trends of the community, among which are the cultural diversity and cultural identity. Cultural diversity refers to the variety of communities of a shared cultural identity in a determined region or the world as a whole (Newman and Jennings, 2008). Collective cultural identities enrich cultural diversity and cultural diversity has intrinsic values for development (Newman and Jennings, 2008). Apart from economic growth, cultural diversity provides fulfilling intellectual, moral, spiritual, prosperous and profound ways of lives in which can only be experienced by those who appreciate their cultural identity (Larrain; 1994; Inglis, 2001; Newman and Jennings, 2008).

Based on the literature study, the fundamental purpose of SIA is to forecast the social change, before development to develop mitigation strategies for improvements. By appreciating existing cultural diversity, proposed development able to relate and complement the original identity of the place and the community. This way, approaching the community for public participation would be less insurmountable.

Profiling in SIA involved evaluation on the social environment that comprises of demographic and socio-economics details, residents' activities, institutional structure, current conditions and critical features which associated with the social trends of the people. The processes of profiling also cover regional demographic and economic details. The profiling phase explains the relationship between social trends and existing issues of the site. The outcome of the profiling process is an evaluation of social changes forecasted before development. The social changes are dependable on social factors used as measurable indicators throughout the assessment.

\subsection{Statistical Findings}

This section shows the inferential analyses indicating existing issues in Bako Peninsula as well as recommendations to be instilled in forthcoming development towards solving the issues. Prior to the inferential analyses, description on demographic and socioeconomic 
profiles of the respondents reviewed cultural diversity and social trends of the respondents.

Among 14 states in Malaysia, Sarawak is the largest state located on the island of Borneo. The area covers $124,449.51$ square kilometers which made approximately $94 \%$ of the total size of Peninsular Malaysia, yet with less than $10 \%$ of its total population. The highest population of Sarawak, that is 617,887 settled in the administrative district of Kuching (Sarawak State Planning Unit, 2012). Bako Peninsula located approximately 40 kilometers away from Kuching City Centre. Located in the north part of Bako Peninsula is one of the oldest national parks in Sarawak, also known as Bako National Park. Additionally, industrial activities were highly emerging in the brink of the south part of the peninsula. The total population of Bako Peninsula was 16,559 in 2013. By applying 1.9\% growth rate of Kuching population based on the latest census, the estimated population of Bako Peninsula in 2030 is 22,803 .

\subsection{Demographic and Socioeconomic Trends}

$95.7 \%$ of the total samples were Malays, $1.7 \%$ were Iban, and $1.6 \%$ were Chinese. The few remaining respondents were Bidayuh, Melanau and Indians. The Malays highly dominated the multiethnic population in Bako Peninsula. $46.3 \%$ were male respondents, and $53.7 \%$ were the female respondent. $62 \%$ of the respondents were 40 years old while the remaining respondents vary between 15 to 39 years old. According to a few of the village chiefs, the majority of young residents ranging between 20 to 35 years old moved out of the Peninsula due to lack of career opportunities.

In Malaysia, working age vary between 15 to 64 years old (Department of Statistics Malaysia (2010). $26 \%$ of the respondents were self-employed, $8.1 \%$ were government employees, and $27.2 \%$ were private employees. The remaining respondents were students, retirees and housewives. $21.0 \%$ of the respondents were unemployed although they were within their working age. On the other hand, $4.3 \%$ of the respondents were employed despite reached their retirement age. The majority of the unemployed respondents were female. $10 \%$ of the samples were housewives, and nearly all of the housewives were still within their working age. The highly mentioned reasons of unemployment were the household commitment $(27.0 \%)$ followed by lack skills and low education levels $(21.8 \%)$, and merely personal choice $(17.1 \%)$. It was later discovered that $64 \%$ of the respondents who never had formal education were female. The statistics indicated that there was a deficiency in career opportunities. The statistics also suggested that the female respondents unlikely employed in the professional environment highly due to domestic responsibilities and restricted mobility.

There were four sectors of economy identified in the samples which generalized the professional fields of the locals in Bako Peninsula. There was the primary sector which harvests goods from the Earth and secondary sector which manufacture the goods. The tertiary sector refers to the service industry, and the quaternary sector pertained to intellectual activities. The majority (13.6\%) of the respondents who were self-employed worked in the primary sector of the economic activities. Among them were fishermen, farmers, fishmongers, prawn farm owners and Bako National Park employees. $15.2 \%$ of the respondents who worked in the secondary sector served as factory workers, factory 
operators, factory supervisors, welders, construction workers, contractors, carpenters, mechanics, tailors and shrimp paste makers. $29.2 \%$ of the respondents worked in the tertiary sector. Commonly they were entrepreneurs, grocers, salesmen, retailers, caterers, cleaners, drivers, boatmen, restaurant workers, tour guides, policemen, marine officers, engineers, clerks and security guards. $3.4 \%$ of the respondents who worked in the quaternary sector were mostly librarian, teachers and lab assistants. The statistics suggested that professions that associated to the existing natural environment highly convenient to the locals, particularly those who were self-employed. The analysis also discovered that majority of the villagers in the northern part of the Bako Peninsula were fishermen. Some of the villages in Bako Peninsula were recognized as Fishermen Villages, signifying one of the strongest cultural identity in Bako Peninsula.

\subsection{Association between Settlement Types and Accessibility to Social Amenities}

Chi-Square for Independence Tests determined the relationships between settlements types and accessibility to 12 social amenities. The null hypothesis was there were no significant relationships between settlement types and accessibility to social amenities.

In terms of institutional amenities, there were statistically significant relationships between Settlement Types and Accessibility to Primary School, X2(9) $=23.564, p=0.005$; between Settlement Types and Accessibility to Secondary School, X2(9) $=23.734, p=0.005$; and between Settlement Types and Accessibility to Kindergarten, $X 2(9)=38.783, p=0.001$ $<0.05$.

In terms of residential amenities, there were statistically significant relationships between Settlement Types and Accessibility to Multi-Purpose Hall, X2(9) $=70.009, p=0.001$; between Settlement Types and Accessibility to Community Hall, X2(9) $=66.080, p=0.001$; and between Settlement Types and Accessibility to Library, X2(9) = 22.766, $p=0.007<0.05$.

In terms of health services, there were statistically significant relationships between Settlement Types and Accessibility to Health Clinics, X2(9) $=56.663, p=0.001$; between Settlement Types and Accessibility to 1Malaysia Clinics, $X 2(9)=44.327, p=0.001$; and between Settlement Types and Accessibility to Cemetery, X2(9) $=64.500, p<0.05$.

Finally, in terms of religious facilities, there were statistically significant relationships between Settlement Types and Accessibility to Mosque, X2(9) $=79.419, p=0.001$; between Settlement Types and Accessibility to Buddhist Temple, $X 2(9)=42.1599, p=0.001$; and between Settlement Types and Accessibility to Church, X2(9) $=23.912, p=0.004<0.05$.

The statistical outputs suggested that level of accessibility to the 12 social amenities significantly vary between fisherman villages, traditional villages, low-cost housing area and modern housing area. Therefore, the statistical results rejected the null hypothesis. Respondents who lived in fishermen villages, traditional villages and low-cost housing area were more likely inaccessible to the social amenities as compared to respondents who lived in the modern housing area.

\subsection{Association between Settlement Types and Infrastructure Issues}


Chi-Square for Independence Tests determined the relationships between settlements types and five existing infrastructure issues. The null hypothesis was there were no significant relationships between settlement types and infrastructure issues.

In terms of supply, there were statistically significant relationships between Settlement Types and Water Supply Shortage, X2(9) $=27.928, p=0.001$; between Settlement Types and Electricity Shortage, $X 2(9)=11.263, p$; and between Settlement Types and Telecommunication Shortage, X2(9) $=12.275, p=0.010<0.05$. In terms of utilities, there were statistically significant relationships between Settlement Types and Drainage Issue leading to Flash Flood, X2(9) $=24.348, p=0.001$; and between Settlement Types and Solid Waste Problem, $X 2(9)=25.743, p=0.001<0.05$.

The statistical outputs suggested that presence of infrastructure issues significantly vary between fisherman villages, traditional villages, low-cost housing area and modern housing area. Therefore, the statistical results rejected the null hypothesis. Respondents who lived in fishermen villages and traditional villages were more likely to face infrastructure issues as compared to respondents who lived in the low-cost housing area and modern housing area.

\subsection{Association between Economic Activities and Benefits of Natural Resources}

Chi-Square for Independence Tests determined the relationships between economic activities and benefits of natural resources. The null hypothesis was there were no significant relationships between economic activities and benefits of natural resources.

There were no significant relationships between Economic Activities and Forest Benefit, $X 2(4)=3.022, p=0.554$; between Economic Activities and Wetland Benefit, $X 2(4)=5.843$, $p=0.211$; and between Economic Activities and Wildlife Benefit, $X 2(4)=0.911, p=0.923>$ 0.05 . Additionally, there were no significant relationships between Economic Activities and Crop Farming Practice, $X 2(4)=5.950, p=0.203$; and between Economic Activities and Livestock Farming Practice $X(4)=1.893, p=0.755>0.05$. However, there were statistically significant relationships between Economic Activities and Marine Life Benefit, X2(4) = 18.661, $p=0.001$; and between Economic Activities and Fishing Practice, $X 2(4)=35.812, p$ $=0.001<0.05$.

The statistical outputs suggested that benefits in the forest, wildlife, wetlands, crop farming and livestock farming did not vary between respondents working in the primary sector, secondary sector, tertiary sector and quaternary sector. However, the statistical outputs also suggested that benefits of marine life and fishing practice significantly vary between respondents working in the primary sector, secondary sector, tertiary sector and quaternary sector. Therefore, the null hypothesis was rejected. The respondents working in the primary and secondary sector were more likely to benefit from marine life and fishing practice.

\subsection{Correlations between Household Income and Income Percentage of Natural Resources}

Spearman Rho Correlation Tests determined correlations between household income categories and percentage of income from natural resources. The null hypothesis was there 
were no significant correlations between household income categories and percentage of income from natural resources.

There were no significant correlations between Household Income Categories and Percentage of Income from Forest, rho $=0.039, p=0.528$; and between Household Income Categories and Percentage of Income from Wildlife, rho $=0.148, p=0.160$. However, there were statistically significant and negative correlations between Household Income Categories and Percentage of Income from Wetland, rho $=-0.16, p=0.012$; and between Household Income Categories and Percentage of Income from Marine Life, rho $=-0.131, p$ $=0.003$.

The statistical outputs suggested variability in household income did not attribute to variability in percentage of income profited from forest and wildlife. However, the statistical outputs also suggested that variability in household income did significantly attributed to variability in percentage of income benefited from wetland and marine life. Therefore, the null hypothesis was rejected. Respondents with low household income were likely to receive financial profit from wetland and marine life.

\subsection{Differences in Potential Participation Preference between Gender and Employment Status}

Mann-Whitney U Tests and Kruskal-Wallis Tests determined differences in potential participation preferences in accommodation, cultural exhibition, retail, community gallery and outdoor activities between-groups of gender and employment status. The null hypothesis was the groups in gender and employment status had the same distribution in potential participation preference in accommodation, cultural exhibition, retail, community gallery and outdoor activities. That is, the level of preferences were the same between-groups of gender and employment status.

There were no statistically significant differences between Male and Female in terms of Preference in Accommodation, $U=158433.5, p=0.283$; Preference in Cultural Exhibition, $U$ $=162136.5, p=0.683$; and Preference in Community Gallery, $U=154579.5, p=0.068$. Additionally, there were no statistically significant differences between Employed and Unemployed respondents in terms of Preference in Cultural Exhibition, $U=153035.0, p=$ 0.914 .

However, there were statistically significant differences between Male and Female in terms of Preference in Retail, $U=152817.5, p=0.037$; and Preference in Outdoor Activities, $U=142366.0, p=0.001$. Male respondents were more likely to prefer Retail and Outdoor Activities as compared to female respondents. Additionally, there were statistically significant differences between Employed and Unemployed respondents in terms of Preference in Accommodation, $U=142677.0, p=0.041$; Preference in Retail, $U=141187.0,0.020$; Preference in Community Gallery, $U=141403.0, p=0.019$; and Preference in Outdoor Activities, $U=135639.0, p=0.001$. Employed respondents were more likely to prefer Accommodation, Retail, Community Gallery and Outdoor Activities as compared to Unemployed Respondents. 


\subsection{Factors Influencing Potential Participation Preference}

The additional descriptive analysis was conducted to determine community issues that influence potential participation indicated ten highest community issues selected by the respondents. The community issues addressed in Likert Scale questions inquired respondents to select among 1=Very Insignificant, 2=Fairly Insignificant, 3=Moderate, 4=Fairly Significant, and 5=Very Significant. The five highest selected community issues were lack leadership quality $(M=4.07)$, conflicting objectives among landowners $(M=4.00)$, conflicting objectives among leaders $(M=3.96)$, lack women leadership $(M=3.90)$, and lack business minded members $(M=3.88)$. The remaining five include lack tourist-friendly members $(M=3.78)$, lack confidence among members $(M=3.77)$, exclusion on due to socioeconomic status inequality $(M=3.76)$, exclusion due to ethnic disparity $(M=3.73)$, and exclusion due to political division $(M=3.70)$.

\subsection{DISCUSSIONS}

The inferential statistics identified significant issues relating to cultural diversity and social trends of Bako Peninsula. The first issue was that underprivileged residents particularly residents in fishermen villages were most likely inaccessible to social amenities and facing deficiency of infrastructure and utilities. Additionally, residents working in the primary sector of the economic activities were gaining economic benefits from the natural resources particularly wetlands, marine life and fishing activities. Finally, potential participation varies by gender and employment status. Female respondents were less interested in retail and outdoor activities as compared to male respondents yet had the same level of interest in accommodation, cultural exhibition and the community gallery. Additionally, unemployed respondents display a similar level of interest with employed respondents in the cultural exhibition. Based on the findings, two significant aspects which need to be further inventoried and instilled in forthcoming development were limited exploitation of natural resources and rural-income generating activities.

Exploitation of the natural resources needs to be limited and carefully managed. Inconsideration may lead to a destruction of the natural environment, which is the primary source of income for the fishermen. If the fishermen no longer benefit from the natural environment, fishermen would no longer survive, and one of the strongest cultural identity of Bako Peninsula would gradually disappear.

Entrepreneurship and employment opportunities for the female residents should be developed through activities highly related to the local-context of Bako Peninsula. The activities should be able to be operated at home. Further inventories should be conducted on rural income-generating activities which can be carried out from home. Mobility of the female residents can be increased through efficient public transport system. Institutions to develop leaderships, talents and independences among female members should also be implemented in the attempt to increase labor force participation rate among female residents. 


\subsection{Conclusion}

The research discovered social trends and cultural diversity of Bako Peninsula through demographic and socioeconomic details of the respondents. The inferential statistics determined that among issues in Bako Peninsula were accessibility to social amenities and deficiency in infrastructure and utilities at the underdeveloped areas of Bako Peninsula. The analysis also found that there existed diversity in sources of income and potential participation preference in prospective activities. Participation of the residents in the survey questionnaires assists the research to identify improvements necessary to ease the residents' everyday activities. Additionally, the discovery of potential participation preference in prospective activities helped to forecast range of employment opportunities before development. Factors that contributed to residents' potential participation in prospective activities also determine necessary institutions to be introduced to elevate the quality of lives of the residents.

The future direction of the research is to identify in detail the locations that exist a lack of accessibility to social amenities and deficiency in infrastructure and utilities for further inventories in the attempt to indicate suitable solutions. The research will also forecast the employment opportunities based on the potential participation as well as upcoming proposed development.

\section{References}

Ahmad, A. (2009). Social impact assessment in Malaysia. Shah Alam: Malaysian Association of Social Impact Assessment.

Colantonio, A., \& Dixon, T. (2009). Measuring Socially Sustainable Urban Regeneration in Europe. Oxford: Oxford Brookes University.

Granger, R. (2010). What now for urban regeneration?. Proceedings of the ICE - Urban Design and Planning, 163(1), 9-16.

Hanaki, K. (2008). Urban environmental management and technology. Tokyo: Springer Verlag.

Inglis, T. (2001). Local Belonging, Identities and Sense of Place in Contemporary. Ireland. Retrieved February 2, 2014. www.ucd.ie

Larrain, G. (1994). Ideology and Cultural Identity. Cambridge: Polity Press in association with Blackwell Publishers.

Loden, M., \& Rosener, J. B. (1991). Workforce America!: Managing Employee Diversity as a Vital Resource. Homewood: Business One Irwin.

Newman, P., \& Jennings, I. (2008). Cities as Sustainable Ecosystem. Principles and Practices. Washington District of Columbia: Island Press.

O'Neil, D. (2006). Human Culture: What is Culture?. Retrieved February 28, 2014. www.anthro.palomar.edu. 